\title{
Overcoming: A Concept Analysis
}

\author{
Barbara L. Brush, PhD, RN, Keri Kirk, MS, Laura Gultekin, MS, FNP-BC, and Janet M. Baiardi, PhD, FNP-BC \\ Barbara L. Brush, PhD, RN, is Associate Professor and Co-coordinator of the Family Nurse Practitioner Program, \\ University of Michigan School of Nursing, Ann Arbor, MI, Keri Kirk, MS, is Project Coordinator, Michigan Center for \\ Health Intervention (MICHIN), Laura Gültekin, MS, FNP-BC, is Research Associate, University of Michigan, and Janet M. \\ Baiardi, PhD, FNP-BC, is Associate Professor, University of Detroit Mercy.
}

\author{
Keywords \\ Overcoming, resilience, \\ homelessness

\section{Correspondence} \\ Barbara L. Brush, PhD, RN, $400 \mathrm{~N}$. \\ Ingalls, University of Michigan, \\ School of Nursing, Ann Arbor, MI \\ 48109. \\ E-mail: brushb@umich.edu
}

\begin{abstract}
BACKGROUND. Nurses often work with individuals and populations striving to improve or maintain the quality of their lives. Many, struggling from complex health and social problems, are challenged to surmount barriers to achieve this goal. The growing number of homeless families in the United States represent one such cohort.

AIMS. To develop an operational definition of overcoming and explicate its meaning, attributes, and characteristics as it relates to homeless families.

METHODS. Using the concept analysis method described by Walker and Avant, along with an extensive literature review, and sample cases pertaining to family homelessness, we delineated the defining attributes, antecedents, consequences, and empirical referents of the concept, overcoming.

CONCLUSION. The results of this concept analysis, particularly the relationship of overcoming to family homelessness, provide guidance for further conceptualization and empirical testing, as well as for clinical practice.
\end{abstract}

\section{Introduction}

Nurses often work with individuals and populations with complex health and social problems, assisting them to promote health, whether in terms of their mental or physical states, their environments, or their social habits, lifestyles, and choices. This interactive process can be fraught with nuanced meaning and approaches that may differ between patients and providers. In a recent qualitative study exploring the lives of homeless mothers, for example, study participants often spoke of "overcoming" their situations as a desired outcome (Gültekin, Brush, Baiardi, Kirk, \& Lapides, in press). The discussion that then ensued included measures to reach that aim (e.g., securing stable housing and employment and/or completion of or furthering education) and what services and support were needed to promote them. As data from the focus groups were analyzed, moreover, it was also apparent that the perceptions of need between providers and service recipients was discordant, that is, homeless women identified and prioritized barriers and obstacles they needed to overcome differently from those anticipated by the providers. Thus, while "overcoming" conjured up images of participants' rising above an undesirable situation and moving toward brighter and better futures for themselves and their children, the term meant different things depending on one's perspective and life situation. This is also true in the literature. Often used interchangeably with terms such as resilience, survival, adaptation, or resourcefulness, overcoming has yet to be systematically explored or defined as a concept in nursing.

Utilizing the concept analysis method described by Walker and Avant (2005), we explicate the meaning of overcoming and examine its attributes and characteristics. Sample cases from our research and practice with homeless families illustrate the concept further and help us develop an operational definition. The results of this analysis will enhance understanding of the concept and its theoretical and practical implications for nursing more broadly. 


\section{Definitions and Uses of the Concept}

According to the American Heritage Dictionary (2009), the word "overcoming" is derived from the Old English word, ofercuman, and means to get the better of; to defeat (another) in competition or conflict; to conquer, prevail over, or surmount; or to overpower or overwhelm, as with emotion. Synonyms such as vanquish, survive, best, beat, conquer, and hurdle and antonyms such as give in, surrender, relapse, and yield, connote a process of winning over losing, success over failure, or surmounting rather than succumbing to.

Certain individuals have come to symbolize the concept of overcoming and serve as models of inspiration to others. For example, Helen Keller, in the face of seemingly insurmountable physical disabilities, went on to become a preeminent author and activist who penned the now famous "All the world is full of suffering. It is also full of the overcoming of it" (Keller, 2000). Like Keller's victorious navigation over blindness and deafness, so too have others overcome significant social barriers and personal adversity to achieve success (Davis \& Sturdevant, 2002) or ensured survival (Penner, Ferdinand, \& Carter, 2009).

The process of overcoming has also been popularized in songs of protest, activism, and/or spiritual awakening as well as in a host of self-help books from binge eating (Hirschmann \& Munter, 2008) to problems in everyday life (Kushner, 2006). The Civil Rights movement's key anthem, "We Shall Overcome," signifies surpassing barriers to racial discrimination. The song's lyrics were adapted from Charles Tindley's 1900 gospel song, "I'll Overcome Someday," which describes surmounting temptation and the "thousands of snares set for me" through prayer and faith (Ruehl, n.d.). Tindley's prayerful discourse mirrors references to overcoming in the Bible's New Testament, Book of John, where it is noted that "For whatsoever is born of God overcometh the world: and this is the victory that overcometh the world, even our faith" (I John I 4,5). References such as these highlight that one's ability to overcome is a process that necessitates willpower, internal strength, and motivation to change an existing condition for another more enlightened or more freeing one.

As in more public uses of the concept, the term "overcoming" has also been used across health disciplines to define one's ability to work through or surmount an issue, problem, obstacle, or situation such as addictive behaviors (Dende 8 Kline, 1995; Hodgins, 2001; Houston et al., 2008), physical or mental health illnesses or disorders (Ledoux \& Gorman, 2001; Pinquart, Duberstein, \& Lyness, 2007; Shellman \& Mokel, 2010; Strickland, Hodges, North, \& Weghorst, 1997), or barriers to care access and quality (Robert Wood Johnson Foundation, 2008; Schooley, Horan, Lee, \& West, 2010; Tod \& Joanne, 2010). In the pharmacology literature, the term is also used to denote ways to surpass resistance and maximize drug effect on target illnesses (Ahmad, Barnes, \& Adcock, 2008; Marwick, Adcock, \& Chung, 2010; Petersen, Peyton, Minna, \& Wang, 2010).

Typically portrayed as a difficult process, overcoming is an active and conscious effort, made willingly and in response to a desire to move beyond one state to a better alternative or situation. In some instances, the process of overcoming leads to recovery and reparation from the issue such that the condition is no longer problematic (Henderson, 2010; Polcin, Korcha, Bond, Galloway, \& Lapp, 2010; Van Vliet, 2009). Indeed, the terms "adaptation," "resilience," and "survival" have been used interchangeably to describe the process of overcoming.

Earvolino-Ramirez (2007) defined resilience as the ability to bounce back or cope successfully despite substantial adversity, implying that there has been a deviation from a more desired norm to which one hopes to return. Tusaie, Puskar, and Sereika (2007) used the term when describing rural adolescents' ability to cope with emotional distress, describing the process as "the capability to adapt better than expected in the face of significant adversity or risk" (p. 54). Thus, resilience implies a process of hurdling resistance, and in doing so, gaining strength against future stressors, challenges, crises, or trauma, much like a microbe develops resilience over time to an antibiotic and ultimately adapts to and survives its environmental conditions. Survival in the case of the microbe is the ability to live despite a life-threatening event but survivorship has also been associated with life-altering incidents such as sexual abuse, violence, and homelessness (Bender, Thompson, McManus, Lantry, \& Flynn, 2007; Peck, 2008). Adaptation and survival are thus consequences of resiliency (Hernandez, Gangsei, $\delta$ Engstrom, 2007) while resiliency is an important individual characteristic in the process of overcoming.

\section{Defining Attributes and Definition of Overcoming}

Defining attributes, similar to signs and symptoms, are critical characteristics that help to differentiate one 
concept from another related concept and clarify its meaning (Walker \& Avant, 2005). Three key defining attributes have been identified for the concept overcoming: (a) an ability to recognize or acknowledge that a behavior, situation, event, or problem exists and is undesirable, impeding, or unhealthy; (b) demonstrated readiness and determination to change or surmount the behavior, situation, event, or problem; and (c) belief that efforts to change or surmount the behavior, situation, event, or problem will improve one's future life quality. Overcoming is thus defined as a deliberate and thoughtful process of changing or conquering a self-perceived problematic circumstance, challenge, or adversity in order to live a healthier and happier future existence.

\section{Antecedents}

Walker and Avant (2005) define antecedents as the events or attributes that must arise prior to a concept's occurrence. In the process of overcoming, an individual must first identify the existence of and need to change a current behavior, situation, event, or problem. Thus, in line with Bandura's (1977) definition, behavior change and maintenance are a function of one's expectations about the outcomes of engaging in a behavior and the expectation about one's ability to execute that new behavior. Outcome and efficacy expectations include beliefs about whether or not the desired outcome will occur and the individual's perceived capacity to perform relevant tasks toward that aim (Bandura, 1977). Self-efficacy, therefore, plays a significant role in overcoming; individuals need to believe in themselves and their ability to make and sustain a change in their situation in order to overcome it. It is generally accepted that individuals with low self-efficacy are less likely than those with high self-efficiency to consider overcoming their situations, and when they do, to be successful (Bandura 8 Locke, 2003; Stretcher, DeVellis, Becker, \& Rosenstock, 1986; Vancouver, Thompson, \& Williams, 2001; Yeo \& Neal, 2006).

Change is paramount to overcoming, which, as delineated in Prochaska and DiClemente's (1982) Stages of Change Model, is a process that evolves through five distinct phases and denotes one's readiness to engage in overcoming an identified behavior, situation, event, or problem. The first stage, precontemplation, is a time when there is no foreseeable readiness to change one's current behavior, situation, event, or problem, largely because the individual is not fully aware of the need for remedy. Stage two, or the contemplation stage, signifies a period when a person gives serious thought to overcoming a behavior, situation, event, or problem but does not commit to action. Should this stage be met, an individual next moves to the preparation stage, in which he intends to make necessary changes and then begins to incorporate small behavior changes into his life. Still, it is not until the fourth, or action stage that individuals modify their behavior or environment to overcome their situations. Modifications in this stage are visible and often receive external recognition from others. The final stage is where individuals continue to work to maintain their behavioral change and prevent relapse.

It is important to note that no matter how well intended an individual may be, relapse and recycling through the stages occurs frequently and is a well-documented part of the struggle to overcome (Prochaska, DiClemente, \& Norcross, 1992). The reality of relapse requires that an individual be resilient and flexible, particularly since the process of overcoming is neither linear nor absolute on first attempt. Overcoming also requires that individuals have optimism and/or hope for a better future than the present and past lives that define them. It is this hope that serves as motivation for the difficult stages of change, thus helping to move the individual beyond adapting to or surviving a difficult situation to acquiring a life of purpose and meaning. Perceived social support also serves as motivation during this process. Once change is in progress, individuals must believe that their achievements are supported by significant others, agencies, or systems in both the short and long term.

For optimum success in overcoming an identified source, therefore, individual characteristics must ally with environmental factors to support the process. Social factors that predict one's ability to overcome include access to services that can assist them with their individual needs, family or friend support, and a broader community social network. Although the need for environmental support may vary with the degree and complexity of the issue, problem, or situation at hand, the individual needs to perceive that it is available and helpful in the process of overcoming. For example, Cone and Waters (2006) described the process of reconnecting in their grounded theory study of formerly homeless mothers and found that social interactions were critical to resolving homelessness. Likewise, Tischler (2008), examining the resettlement and reintegration experiences of single homeless mothers after rehousing, noted that improv- 
ing one's physical surroundings (e.g., living away from violent neighborhoods and/or relationships) helped one maintain the ability to overcome homelessness. Their findings mirrored many of those in our study (Gültekin et al., in press). Several participants in our study had been homeless multiple times; individuals suffering from substance addiction, caring for multiple children, and lacking intimate partner, family, or friend support were particularly vulnerable to repeat homelessness. The inability to overcome the challenges of these component issues and receive support in doing so precluded their ability to overcome homelessness as an outcome.

\section{Consequences}

Consequences are those events or incidents that can occur as a result of the occurrence of a concept and that can often stimulate new ideas or avenues for research pertaining to certain concepts (Walker \& Avant, 2005). Possible consequences of overcoming include an individual's return to a more stable and better quality of life, finding hope and meaning in life, and moving beyond a difficult situation or circumstance toward a healthier and more satisfactory future. This is generally a positive process yielding positive outcomes.

\section{Empirical Referents}

Empirical referents are measurable ways to demonstrate the occurrence of the concept (Walker \& Avant, 2005). There are no current measures of overcoming; however, measures of related constructs are available that may help quantify the process and its outcome. Below, we elaborate on the empirical referents for categories of the related phenomena of resiliency, hope, optimism, self-efficacy, and perceived social support on the process of overcoming. Although the literature is extensive, we have limited the discussion to the use of these constructs with the population of interest.

Resilience, rooted in either a psychological or physiological perspective (Tusaie \& Dyer, 2004), has been described as the ability to bounce back from some stress event (Earvolino-Ramirez, 2007; Smith et al., 2008). Much of the research conceptualizes resilience as a positive attribute and has focused on children and adolescents (Haase, 2009). With regard to its influence on overcoming, resilience is seen as an important individual characteristic necessary for the process of overcoming.
In a review of instruments purporting to measure resilience, Ahern, Kiehl, Sole, and Byers (2006) noted that while many instruments measured resilience as a protective factor, they varied considerably in internal consistency and reliability. They argued that only Wagnild and Young's (1993) Resilience Scale (RS) demonstrated adequate reliability and validity across age groups and that it measured the construct of resilience as it related to personal competence and acceptance of self and life. Indeed, Rew, Taylor-Seehafer, Thomas, and Yockey (2001) found the RS useful in examining correlates of resilience in homeless adolescents, concluding that hopelessness, loneliness, and life-threatening behaviors were negatively associated with resilience. Interestingly, they also found that hopelessness and connectedness as a means of social support explained $50 \%$ of the variance in resilience scores among their study participants.

In her essay on stress, coping, and hope, Folkman (2010) discusses the interrelatedness of the three concepts and her final assumptions that (a) hope is essential for individuals coping with longstanding and difficult periods of psychological stress; and (b) hope needs to be nurtured in order to sustain itself during trying episodes, events, and/or situations. Thus, the relationship between hope and coping, as defined earlier by Lazurus and Folkman (1984), is a dynamic and reciprocal one that has clinical applicability for nurses working with homeless families coping with multiple stressors (Finfgeld-Connett, 2010). Measures of hope are important indicators of one's will to overcome and equate with Herth's $(1992,1996)$ definition of hope as a multidimensional concept essential to human life. The 12-item Herth Hope Index (Herth, 1996) has been used to measure overall levels of hope among homeless family members over time and demonstrated both internal consistency and validity. Herth (1996) found that hope levels among family members were low initially when families entered shelters, rose significantly as they moved from shelter to housing, and then leveled off once they were stabilized. Like overcoming more generally, however, Folkman (2010) cautions researchers that hope "waxes and wanes, is contextual, and is complex" (p. 902). Measures of hope, therefore, can provide important information at points in time but should be interpreted in a broader context with other defining attributes.

Carifio and Rhoades (2001) differentiate hope from optimism and note that individuals can be optimistic and hopeful, optimistic and hopeless, pessimistic and hopeless, or pessimistic and hopeful. In other words, 
though one might ideally strive to be hopeful and optimistic, hope and optimism can exist separately from one another. In contrast to hope, optimism is a trait that influences how an individual perceives the future. Optimistic individuals think positively about the future and optimism has been found to have a positive influence on health and well-being (Conversano et al., 2010). As with instruments measuring levels of hope, measures of optimism, such as the 12-item Life Orientation Test (Scheier \& Carver, 1985) are often used with other measures (e.g., Perceived Stress Scale, the Health-Promoting Lifestyle Profile II, or other measures of scale) to determine one's optimism relative to his ability and belief to cope with life experiences (Ferguson \& Goodwin, 2010; Gill \& Loh, 2010).

As noted earlier, self-efficacy is essential to the process of overcoming. Derived from social cognitive theory (Bandura, 1977), it relates to the belief in one's personal ability to affect an outcome or change. Numerous instruments have been designed to measure self-efficacy by self-report and often focus on its relative strength or level as it pertains to an identified behavior or situation. Among homeless populations, the role of self-efficacy has been used to predict or describe such phenomena as rule-following behaviors by sheltered homeless youth (Broadhead-Fearn $\delta$ White, 2006), patterns of pap smear screening use by homeless women (Hogenmiller et al., 2007), and smoking behaviors in homeless adults (Arnsten, Reid, Bierer, \& Rigotti, 2004). Epel, Bandura, and Zimbardo (1999) explored self-efficacy and perspectives of time in a cohort of formerly homeless participants, using the data to develop the 20-item Perceived Self-Efficacy Scale (PSES). Designed to measure the specific attributes of job and housing efficacy, higher scores on the PSES corresponded with individuals who were more likely to be future oriented and seek out housing and employment.

Patterson and Tweed (2009) noted that while a large body of evidence supports the relationship between social support and well-being, there is evidence that those struggling with poverty have little if any support mechanisms and may not perceive them in the same ways as non-impoverished individuals. In a study with homeless individuals, for example, they asked participants to rate the level to which support was needed to move out of homelessness. Dividing areas of identified support into three categoriessocial support (e.g., mentor); services (e.g., transportation, social services); and a broader category that included food, housing, and substance abuse services-they found that participants rated housing support most highly. Toro, Tulloch, and Ouellette (2008) also examined social support in a large homeless population using two indices of the Social Network Inventory (Stein, Rappaport, \& Seidman, 1995) to reflect network and perceived social support. Their findings indicated that homeless individuals tended to have lower levels of social support and higher stress levels overall and that those individuals with higher levels of support had fewer psychological symptoms. Interestingly, they also reported that individuals with greater social networks were more likely to abuse substances, thus refuting the hypothesis, at least in this population, that real and perceived social support always enhances healthy behaviors.

\section{Cases Studies}

Three categories of case studies are provided to further expand the concept of overcoming. While cases may be invented or found in the literature, those presented here derive from actual examples in our work with homeless families. Abbreviations used to identify each case are fictitious and are not based on participants' actual names given that focus group data were collected and categorized by group participant number. The model case demonstrates all of the defining attributes of the concept while the borderline case contains most but not all of them. The final contrary case is a clear example of what the concept is not (Walker \& Avant, 2005).

\section{Model Case and Analysis}

$\mathrm{AB}$ is a 24-year-old African American woman living in a subsidized apartment in Detroit, Michigan. In May 2009, she was 9 months pregnant with her second child when her husband physically assaulted her. Fearing further harm to herself and her 2-year-old son, she left her home with only $\$ 10$ in her pocket, the clothing on her back, and two diapers. She immediately sought refuge at a women's shelter, frightened and embarrassed by her situation and in full recognition that being homeless with a baby on the way was a desperate situation. Within days of becoming homeless, she also reached out to family, but was disappointed by the lack of support and assistance they were able or willing to offer. Quickly realizing that she was on her own and that any change in her situation would be self-motivated, she applied for emergency 
housing assistance, found legal aid services, and discovered a variety of community resources aimed at supporting women in similar circumstances. She did not wait for others to inform her of available assistance programs, but actively engaged in her own rehousing process. Within 2 months, with the assistance of a service agency geared to supporting homeless families, she and her two young children relocated to an apartment and she enrolled in college to become a social worker, determined to build a better life for her sons and herself. She also continues to attend a weekly program to acquire the skills she needs to make this plan a reality and to create and sustain a support network that she deems critical to her ongoing ability to overcome homelessness.

This model case study fully demonstrates all three attributes of overcoming: recognition of the need to change a current behavior, situation, event, or problem; demonstrated readiness and determination to change or surmount the behavior, situation, event, or problem; and belief that efforts to change or surmount the behavior, situation, event, or problem will improve one's future life quality. First, our model case participant identified that her living situation was unhealthy and potentially harmful to herself and her child. While leaving the harmful environment was sudden and unexpected, she was able to locate emergency shelter and then attempted efforts to seek assistance. When her family was unable to provide support and the shelter system revealed itself unprepared to meet the needs of her growing family, she shifted her efforts to other resources in an effort to overcome her circumstances. Her resiliency in the face of repeated barriers allowed her to take action that led to change. She was able to successfully secure and maintain housing and made additional changes (e.g., by continuing her education and expanding her life skills) with the hope that her life and those of her children would improve. She not only overcame her own domestic situation, but was so well versed in community resources that she was able to offer guidance and encouragement to her peers and serve as an inspiration for their journeys toward overcoming homelessness.

\section{Borderline Case and Analysis}

CD, a 30-year-old Hispanic female, was recently rehoused, along with her 8-year-old daughter, after living in a homeless shelter for several months. This is her second episode of homelessness in less than a year and she is now 9 months pregnant with her third child from her current and recently imprisoned male partner. Another child, a 2-year-old son, is currently in medical foster care because of a cardiac condition deemed too complicated to manage while she was living in a shelter or temporarily residing with acquaintances. Both episodes occurred after a partner, on whom she was financially dependent, was unable to support her and her children. Though new to the Detroit area, CD was highly motivated to find housing and locate available resources so that she could reunite her family. During the process of overcoming homelessness, however, CD was frustrated to learn that she had to seek out resources for herself. She readily utilized available services but relied on others to direct her toward them. While her goal of rehousing was achieved and she was reunited with her son, she had no long-term plans for maintaining stable housing, she was not seeking employment, and she was living day to day.

CD's story exemplifies a borderline case, where only two of the three attributes of overcoming are realized. Once faced with the reality of a homeless shelter and separation from her child, CD recognized and acknowledged the need to change her dire circumstances. She acted upon this by accepting the assistance offered to her at the shelter and actively participated in rehousing efforts. This active participation was key to her successfully securing a place of residence; on the contrary, she was not actively engaged in future planning to remedy the root causes that led to her homelessness on two occasions. By merely substituting her financial dependency from partners to subsidized resources in an effort to abate her current homeless situation, she has not overcome the risk for future episodes of homelessness.

\section{Contrary Case and Analysis}

$\mathrm{EF}$ is a 23-year-old African American female living in a Detroit family shelter with her 2-year-old son. During the focus group sessions, she did not share the circumstances which led to her episode of homelessness but expressed dismay that the local shelter system did not directly aid her in the rehousing process. She spoke of unsympathetic case workers, cold, filthy sleeping conditions, and strict rules and regulations regarding food and meal times. She could not envision a way out of her current situation and when her peers offered suggestions regarding poten- 
tial housing opportunities, she responded negatively, noting that those buildings were in the "wrong part of town" or that she would be unable to afford them. She was tearful and down-trodden, did not speak of her future housing or employment prospects, and displayed little hope for a better living situation for herself and her child.

This final case reflects an absence of the attributes of overcoming. EF recognized that she was in an unfortunate situation, but was not able to acknowledge that there was potential for a better circumstance. She spoke in negative terms and was not personally motivated to seek resources or plan for the future. EF did not believe that she could sustain housing, even when her peers shared that they had been successful with similarly limited resources. In this case, failure to overcome led to a prolonged episode of homelessness, and high risk for recurrence of homelessness in the future.

\section{Implications for Nursing Practice}

Overcoming is a phenomenon that has yet to be sufficiently studied to provide a base for nursing knowledge. Analysis of the concept overcoming helps nurses design clinical interventions that promote the process, contributing to positive physical, psychosocial, and environmental health outcomes. Nurses working with particular populations, such as homeless families, may find overcoming and its attributes integral to assessment and intervention. Our current research suggests, for example, that overcoming is a key element in the ability of homeless mothers to move beyond their current homeless state, identify and change root behaviors that put them at risk for future homeless episodes, and create healthier, happier lives for themselves and their children (Gültekin et al., in press). Clearly, however, this is an area for further clinical nursing research that can extend across settings and individuals.

\section{Conclusion}

A first step toward developing a theory of overcoming is a systematic analysis of the concept. This concept analysis has identified the antecedents, defining attributes, and consequences of overcoming. Overcoming is theoretically defined as a process whereby an individual and/or group acknowledges a behavior, situation, event, or problem and its negative health or social impact, becomes willing to change the behavior, situation, event, or problem, and derives hope that by doing so, one can improve quality of life for oneself and/or others. The next step in the development of the theory of overcoming for nursing is the construction and testing of theoretical relationships between overcoming and outcome variables. Systematic studies of overcoming, whether quantitative or qualitative, can ultimately enhance nursing science and promote health in individuals and populations served.

Visit the Nursing Forum blog at http://www. respond2articles.com/NF/ to create, comment on, or participate in a discussion.

\section{References}

Ahern, N. R., Kiehl, E. M., Sole, M. L., \& Byers, J. (2006). A review of instruments measuring resilience. Issues in Comprehensive Pediatric Nursing, 29, 103-125.

Ahmad, T., Barnes, P. J., \& Adcock, I. M. (2008). Overcoming steroid insensitivity in smoking asthmatics. Current Opinion in Investigational Drugs, 9(5), 470-477.

American Heritage Dictionary. (2009). The American heritage dictionary of the English language (4th ed.). New York: Houghton Mifflin Company.

Arnsten, J. H., Reid, K., Bierer, M., \& Rigotti, N. (2004). Smoking behavior and interest in quitting among homeless smokers. Addictive Behaviors, 29(6), 1155-1161.

Bandura, A. (1977). Self-efficacy: Toward a unifying theory of behavioral change. Psychology Review, 84(2), 191-215.

Bandura, A., \& Locke, E. A. (2003). Negative self-efficacy and goal effects revisited. Journal of Applied Psychology, 88(1), 87-99.

Bender, K., Thompson, S. J., McManus, H., Lantry, J., \& Flynn, P. M. (2007). Capacity for survival: Exploring strengths of homeless street youth. Child $\theta$ Youth Care Forum, 36(1), 25-42.

Broadhead-Fearn, D., \& White, K. M. (2006). The role of self-efficacy in predicting rule-following behaviors in shelters for homeless youth: A test of the theory of planned behavior. Journal of Social Psychology, 146(3), 307-325.

Carifio, J., \& Rhoades, L. (2001). Construct validities and the empirical relationships between optimism, hope, selfefficacy, and locus of control. Work, 19(2), 125-136.

Cone, P. M. H., \& Waters, C. M. (2006). Reconnecting: A grounded theory study of formerly homeless mothers. University of California, San Francisco: Dissertation, MUIUFSD0805-000605.

Conversano, C., Rotondo, A., Lensi, E., Della Vista, O., Arpone, F., \& Reda, M. (2010). Optimism and its impact on physical and mental well-being. Clinical Practice in Epidemiological Mental Health, 6, 25-29. doi: 10.2174/ 1745017901006010025

Davis, W. H., \& Sturdevant, L. (2002). Overcoming: The autobiography of $W$. Harry Davis. Afton, Minnesota: Afton Historical Society Press. 
Dende, J. D., \& Kline, J. D. (1995). Overcoming crack, schizophrenia, and homelessness: A comprehensive management approach. New Directions in Mental Health Services, 65, 53-65.

Earvolino-Ramirez, M. (2007). Resilience: A concept analysis. Nursing Forum, 42(2), 73-82.

Epel, E. S., Bandura, A., \& Zimbardo, P. G. (1999). Escaping homelessness: The influences of self-efficacy and time perspective on coping with homelessness. Journal of Applied Social Psychology, 29, 575-596. doi: 10.1111/ j.1559-1816.1999.tb01402.x

Ferguson, S. J., \& Goodwin, A. D. (2010). Optimism and well-being in older adults: The mediating role of social support and perceived control. International Journal on Aging and Human Development, 71(1), 43-68.

Finfgeld-Connett, D. (2010). Becoming homeless, being homeless, and resolving homelessness among women. Issues in Mental Health Nursing, 31(7), 461-469.

Folkman, S. (2010). Stress, coping, and hope. PsychoOncology, 19, 901-908.

Gill, R. M., \& Loh, J. M. (2010). The role of optimism in health-promoting behaviors in new primiparous mothers. Nursing Research, 59(5), 348-355. doi: 10.1097/ NNR.0b013e318led6bl 1

Gültekin, L., Brush, B. L., Baiardi, J. M., Kirk, K., \& Lapides, S. (UNDER REVIEW). Voices from the street: Understanding the lived experiences of homeless African American mothers. Health and Social Care in the Community.

Haase, J. (2009). Resilience. In S. J. Peterson \& T. S. Bredow (Eds.), Middle range theory: Application to nursing research (2nd ed., pp. 326-362). Philadelphia: Lippincott Williams \& Wilkins.

Henderson, A. R. (2010). A substantive theory of recovery from the effects of severe persistent mental illness. International Journal for Social Psychiatry. Published online July 21, 2010. doi: 10.1177/0020764010374417

Hernandez, P., Gangsei, D., \& Engstrom, D. (2007). Vicarious resilience: A new concept in work with those who survive trauma. Family Process, 46(2), 229-241.

Herth, K. (1992). Abbreviated instrument to measure hope: Development and psychometric evaluation. Journal of Advanced Nursing, 17(10), 1251-1259.

Herth, K. (1996). Hope from the perspective of homeless families. Journal of Advanced Nursing, 24(4), 743753.

Hirschmann, J. R., \& Munter, C. H. (2008). Overcoming overeating: How to break the diet/binge cycle and live a healthier, more satisfying life. Philadephia: Addison-Wesley Publishing Company.

Hodgins, D. C. (2001). Processes of changing gambling behavior. Addictive Behaviors, 26(1), 121-128.

Hogenmiller, J. R., Atwood, J. R., Lindsey, A. M., Johnson, D. R., Hertzog, M., \& Scott, J. C. (2007). Self-efficacy scale for Pap smear screening participation in sheltered women. Nursing Research, 56(6), 369-377.

Houston, T. K., Ford, D. E., Sadasivam, R. S., Ray, M. N., Allison, J. J., Kohler, C. L., \& Ashton, C. M. (2008). Overcoming limits to tobacco control: Using the internet to bridge clinical and public health interventions. AMIA Annual Symposium Proceedings, November 6, 977.
Keller, H. (2000). To love this life: Quotations by Helen Keller. New York: AFB Press.

Kushner, H. S. (2006). Overcoming life's disappointments. New York: Anchor Books.

Lazurus, R., \& Folkman, S. (1984). Stress, appraisal and coping. New York: Springer.

Ledoux, J. E., \& Gorman, J. M. (2001). A call to action: Overcoming anxiety through active coping. American Journal of Psychiatry, 158(12), 1953-1955.

Marwick, J. A., Adcock, I. M., \& Chung, K. F. (2010). Overcoming reduced glucocorticoid sensitivity in airway disease: Molecular mechanisms and therapeutic approaches. Drugs, 70(8), 929-948.

Patterson, A., \& Tweed, R. (2009). Escaping homelessness: Anticipated and perceived facilitators. Journal of Community Psychology, 37(7), 846-858.

Peck, S. (2008). Survivorship: A concept analysis. Nursing Forum, 43(2), 91-102.

Penner, D., Ferdinand, K. C., \& Carter, J. (2009). Overcoming Katrina: African American voices from the Crescent City and beyond. New York: Palgrave MacMillan.

Petersen, S. L., Peyton, M., Minna, J. D., \& Wang, X. (2010). Overcoming cancer cell resistance to Smac mimetic induced apoptosis by modulating cIAP-2 expression. Proceedings of the National Academy of Sciences, 107(26), 1193611941.

Pinquart, M., Duberstein, P. R., \& Lyness, J. M. (2007). Effects of psychotherapy and other behavioral interventions on clinically depressed older adults: A metaanalysis. Aging o Mental Health, 11, 645-657.

Polcin, D. L., Korcha, R. A., Bond, J., Galloway, G. P., \& Lapp, W. (2010). Recovery from addiction in two types of sober living houses: 12-month outcomes. Addiction Research $\theta$ Theory, 18(4), 442-455.

Prochaska, J. O., \& DiClemente, C. C. (1982). Transtheoretical therapy: Toward a more integrative model of change. Psychotherapy: Theory, Research and Practice, 20, 161-173.

Prochaska, J. O., DiClemente, C. C., \& Norcross, J. C. (1992). In search of how people change: Applications to addictive behaviors. American Psychologist, 47(9), 1102-1114.

Rew, L., Taylor-Seehafer, M., Thomas, N. Y., \& Yockey, R. D. (2001). Correlates of resilience in homeless adolescents. Journal of Nursing Scholarship, 33(1), 33-40.

Robert Wood Johnson Foundation. (2008). Overcoming obstacles to health: Report from the Robert Wood Johnson Foundation to the Commission to Build a Healthier America. Retrieved August 16, 2010, from http://www.rwjf.org/ files/research/obstaclestohealth.pdf

Ruehl, K. (n.d.). We shall overcome: History of an American folk song. Retrieved August 30, 2010, from http://folkmusic. about.com/od/folksongs/qt/weshallovercome.htm

Scheier, M. F., \& Carver, C. S. (1985). Optimism, coping and health: Assessment and implications of generalized outcome expectancies. Health Psychology, 4(3), 219-247.

Schooley, B. L., Horan, T. A., Lee, P. W., \& West, P. A. (2010). Rural veteran access to healthcare services: Investigating the use of information and communication technologies in overcoming spatial barriers. Perspectives in Health Information Management, Spring, 1-20.

Shellman, J., \& Mokel, M. (2010). Overcoming barriers to conducting an intervention study of depression 
in an older African American population. Journal of Transcultural Nursing, 21(4), 361-369. doi: 10.1177/ 1043659609360708

Smith, B. W., Dalen, J., Wiggins, K., Tooley, E., Christopher, P., \& Bernard, J. (2008). The brief resilience scale: Assessing the ability to bounce back. International Journal of Behavioral Medicine, 15(3), 194-200.

Stein, C. H., Rappaport, J., \& Seidman, E. (1995). Assessing the social networks of people with psychiatric disability from multiple perspectives. Community Mental Health Journal, 31(4), 351-367.

Stretcher, V. J., DeVellis, B. M., Becker, M. H., \& Rosenstock, I. M. (1986). The role of self-efficacy in achieving health behavior change. Health Education Behavior, 13(1), 73-91.

Strickland, D., Hodges, L., North, M., \& Weghorst, S. (1997). Overcoming phobias by virtual exposure. Communications of the Association for Computer Machinery, 40(8), 34-39.

Tischler, V. (2008). Resettlement and reintegration: Single mothers' reflections after homelessness. Community, Work e Family, 11(3), 243-252.

Tod, A. M., \& Joanne, R. (2010). Overcoming delay in the diagnosis of lung cancer: A qualitative study. Nursing Standard, 24(31), 35-43.

Toro, P. A., Tulloch, E., \& Ouellette, N. (2008). Stress, social support and outcomes in two probability samples of homeless adults. Journal of Community Psychology, 36(4), 483-498.

Tusaie, K., \& Dyer, J. (2004). Resilience: A historical review of the construct. Holistic Nursing Practice, 18(1), 3-8.

Tusaie, K., Puskar, K., \& Sereika, S. M. (2007). A predictive and moderating model of psychosocial resilience in adolescents. Journal of Nursing Scholarship, 39(1), 54-60.

Vancouver, J. B., Thompson, C. M., \& Williams, A. A. (2001). The changing signs in the relationships among self-efficacy, personal goals, and performance. Journal of Applied Psychology, 86(4), 605-620.

Van Vliet, K. J. (2009). The role of attributions in the process of overcoming shame: A qualitative analysis. Psychology and Psychotherapy: Theory, Research, and Practice, 82(2), 137-152.

Wagnild, G. M., \& Young, H. M. (1993). Development and psychometric evaluation of the resilience scale. Journal of Nursing Measurement, 1(2), 165-178.

Walker, L. O., \& Avant, K. C. (2005). Strategies for theory construction in nursing (4th ed.). Upper Saddle River, NJ: Pearson Prentice Hall.

Yeo, G. B., \& Neal, A. (2006). An examination of the dynamic relationship between self-efficacy and performance across levels of analysis and levels of specificity. Journal of Applied Psychology, 91(5), 1088-1 101. 